\title{
Forum
}

\section{A Consultant's view of the NPPF}

\author{
Jonathan Edis* and Elizabeth Stephen
}

From a commercial consultant's viewpoint, the major shift in heritage policy occurred in March 2010 with the replacement of PPG15 and PPG16 by PPS5. The subsequent conversion of PPS5 into Part 12 of the NPPF has created some interesting twists and turns, but in essence we have now had more than two years in which to adapt to a wholly new system. It was PPS5 that introduced the balance between harm - that is, change amounting to the erosion of heritage significance - and wider public benefit, and it was PPS5 that formed a clear link between the overall planning balance and the topic-specific weight to be given to change in the historic environment. For the first time, PPS5 set out a national policy framework within which to deal with the effects of change on the setting of heritage assets. It also demonstrated that a workable policy system could be successfully grafted onto diverse pre-existing legislation without the absolute need for a comprehensive National Heritage Act, albeit the present relationship between policy and legislation can sometimes be uncomfortable.

Part 12 of the NPPF is an abbreviated and less structured form of PPS5, but it contains broadly the same messages. The key development management changes have been translated into the new document with little change, notably those relating to the adoption of a balanced and proportionate

\footnotetext{
* Heritage Collective,

Marylebone Office, 12 Melcombe Place, London NW1 6JJ, United Kingdom jonathan.edis@heritagecollective.co.uk
}

approach to decision making. However, the NPPF does not improve noticeably on PPS5, and it has not taken advantage of the experience of two years of successful experiment since March 2010. Nowhere is this more evident than in the inadequate definition of the types of harm that might be encountered, something that first found expression in the now superseded Policies HE9.2 and HE9.4 of PPS5. Having helpfully created two levels of harm (substantial and less than substantial) to which different policy criteria applied, PPS5 was at least clear and legible. The same two types of harm are described in paragraphs 132 to 134 of the NPPF, but the drafting of this passage is poor and muddled. Worse, the opportunity to provide more detailed descriptions of degrees of harm has been lost. Two years of appeal decisions since March 2010 have established that substantial harm is a rare animal in the heritage jungle - so rare that it can only be contemplated in compelling and exceptional cases. However, harm that is less than substantial comes in many species, and it applies to the vast majority of real-life planning decisions. By sticking to a one-size-fits-all approach when dealing with less than substantial harm, as set out in paragraph 134 of the NPPF, consultants and decision makers are left struggling in a linguistic straightjacket where there is little room for manoeuvre.

The problem is that we know there is harm, but we are not given the words to describe it and convert it into a form where it can be put into the planning balance consistently. We know from recent appeal decisions that 
less than substantial harm can include levels of impact that are also described as significant and considerable, which concentrates a disconcerting number of similar adjectives in a small conceptual space. Lower down the scale we also know that less than substantial harm can accommodate effects which are described as minor, which is easier to swallow. However, the NPPF provides no framework within which to rank these terms, and there is no indication of how to describe the lowest level of harm to be considered under paragraph 134 of the NPPF. To be included in the planning balance at all, it must be harmful, which raises the question of whether words like negligible can be used in this context. Is negligible harm something that weighs in the balance or not? It may be that a revised Practice Guide will come to our aid, or that the promised revision to the Design Manual for Roads and Bridges will throw some light on this matter, but until that happens the majority of development control cases will continue to be assessed and decided on an ad-hoc basis, something that can only be described as a missed opportunity. 